\title{
Toward better prescription drug surveillance in Canada
}

\author{
Kate Smolina PhD, Nav Persaud MD MSc, Steven G. Morgan PhD
}

$\mathrm{W}$ ell-designed systems for monitoring and surveilling pharmaceutical prescribing, dispensing and use can protect patients from harm, prevent medication abuse and improve clinical decision-making. In 2015, Health Canada granted the Canadian Institute for Health Information \$4.3 million to develop a coordinated national approach for monitoring and surveillance of prescription drug abuse. ${ }^{1}$ This presents an opportunity to replace the current patchwork of prescription monitoring programs across the country with comprehensively designed drug information systems to improve individual patient care and population-level medication surveillance.

In many provinces, existing prescription drug monitoring programs focus only on specific drugs, such as controlled substances. They are stand-alone mechanisms with processes for data collection and use that vary widely across jurisdictions. Data from these programs usually are not real time and cannot be linked to other data sources, thus limiting their usefulness for both clinical management and population surveillance. For example, opioid monitoring programs that do not track concurrent use of sedatives, antidepressants or stimulants make it difficult to identify potentially dangerous drug interactions. Failure to capture data on medications that are not part of a monitoring program is a lost opportunity for identifying new, potentially problematic trends in prescription drug use (e.g., the current $8 \%$ annual growth in prescribing of pregabalin and gabapentin, drugs prone to misuse ${ }^{2}$ ). Furthermore, information can be missed if stand-alone systems are based on identifiers (e.g., drivers' licences) and protocols (e.g., paper records) that do not link well - if at all — to other health databases.

Better infrastructure for modernized monitoring and surveillance systems can be found in population-based drug information systems. These databases contain records of every prescription dispensed for every patient in a jurisdiction. Drug information systems collect information at the point of prescribing, dispensing, or both. They allow storage, retrieval and sharing of patient medication profiles in real time.
One of the main purposes of such systems is to facilitate clinical management by giving health care providers information about medication use at the point of care. ${ }^{3} \mathrm{~A}$ drug information system can, for example, alert a pharmacist to duplicate prescriptions or potentially dangerous interactions between a new prescription and others a patient has filled, even at another pharmacy. When integrated with electronic prescribing, the system can let doctors know which prescriptions patients have filled and which not. With built-in feedback mechanisms, data from drug information systems can be used to improve the quality of care. ${ }^{4}$

Canada Health Infoway has invested \$248 million in drug information systems as part of its investment in better electronic health information across Canada. ${ }^{5}$ Currently, five provinces (British Columbia, Alberta, Saskatchewan, Manitoba and Prince Edward Island) have drug information systems that capture prescriptions from almost all pharmacies. Quebec and the other Atlantic provinces are in the process of adopting such systems. ${ }^{6}$

The infrastructure of population-based drug information systems can help Canada's prescription monitoring and surveillance strategy move beyond monitoring alone. Well-designed systems can be used for real-time surveillance, with specific emphasis on data analysis and feedback. This application of drug information systems is often overlooked, despite having the potential to save the health care system millions of dollars annually by preventing adverse drug events, improving productivity of health professionals, increasing adherence to prescription drugs and reducing health system liability. ${ }^{7}$

Restrictive privacy legislation may limit the

\section{KEY POINTS}

- Canada would benefit from comprehensively designed systems for prescription drug monitoring and surveillance.

- Integrating both clinical management and surveillance functionality into population-based drug information systems can improve patient care and public health.

- Implementation of drug information systems is underway in all Canadian jurisdictions, presenting an opportunity for action. 
ability of health care providers to access and share medication data, which reduces the effectiveness of drug information systems. Although concerns for patient privacy when data are collected and shared are justified and important, they should be weighed against the benefits that information can provide to patient safety, quality of care and public health. Different technical and legal solutions are being used by jurisdictions to ensure that personal health data are available only to authorized individuals when they are legitimately needed. ${ }^{8}$

Practice norms are another potential barrier to using drug information systems for prescription monitoring and surveillance. Drug information systems are usually implemented in four phases: community pharmacies, hospitals, outpatient clinics (for integration with electronic medical records for electronic prescribing) and at the point of care (for advanced decision support). At each stage, implementation can represent a substantial change in the workflow of health professionals. To facilitate adoption and meaningful use in clinical practice, technical support and practice guidelines should be provided and should match the realities of how professionals will use the system. ${ }^{9}$

British Columbia's PharmaNet, established in 1995, is an example of a Canadian drug information system. PharmaNet is an online, real-time system administered by BC's Ministry of Health and the College of Pharmacists. Pharmacists are required by law to enter detailed information concerning every prescription dispensed at retail pharmacies, regardless of drug type or patient age, income or insurance status. There are built-in, point-of-dispensation alerts for possible drug interactions, potential dosage errors and duplicate prescriptions.

PharmaNet is associated with a sustained reduction in inappropriate opioid and benzodiazepine prescriptions. ${ }^{10}$ When linked to other systems that track patient outcomes and use of health services, it has enabled numerous research studies on drug use and related harms. ${ }^{11}$ Such research and analysis could be made part of routine surveillance of pharmaceutical prescribing, utilization and outcomes. Further, the College of Physicians and Surgeons of British Columbia is considering making reviewing patients' medication profiles a required standard of care, a policy innovation that is only possible with a drug information system. ${ }^{12}$ However, there are barriers to overcome before that happens: many physicians' offices need to switch to electronic medical records; it takes time and money to integrate PharmaNet into medical record systems; physician access to PharmaNet is not free; and the system is not built for quick and easy referencing, thus taking valuable time away from patient care.

As policy-makers plan a national approach to monitoring prescription drug abuse, they should explore how best to build clinical management and surveillance functionalities into emerging and existing provincial drug information systems. Comprehensive, efficient, userfriendly and well-integrated systems have the potential to substantially advance both patient care and public health. This, in turn, can help pave the way toward safer prescribing, reduced prescription drug abuse and a more patientcentred health care system in Canada.

\section{References}

1. Funding to the Canadian Institute for Health Information to help address prescription drug abuse. Ottawa: Health Canada; 2015. Available: //news.gc.ca/web/article-en.do?nid=974749 (accessed 2015 May 15).

2. Morgan S, Smolina K, Mooney D, et al. The Canadian Rx atlas. Vancouver: Centre for Health Services and Policy Research, University of British Columbia; 2013.

3. Avoiding abuse, achieving a balance: tackling the opioid public health crisis. Toronto: College of Physicians and Surgeons of Ontario; 2010.

4. Bright TJ, Wong A, Dhurjati R, et al. Effect of clinical decisionsupport systems: a systematic review. Ann Intern Med 2012; 157:29-43.

5. The path of progress. 2014-2015 annual report. Ottawa: Canada Health Infoway; 2015.

6. Deloitte. National impact of generation 2 drug information systems technical report. Ottawa: Canada Health Infoway; 2010.

7. Canada Health Infoway. Drug information system busines case: executive report. Ottawa: Canada Health Infoway; 2006.

8. Accessing health and health-related data in Canada. Ottawa: Council of Canadian Academies; 2015.

9. Rozenblum R, Jang Y, Zimlichman E, et al. A qualitative study of Canada's experience with the implementation of electronic health information technology. CMAJ 2011;183:E281-8.

10. Dormuth CR, Miller TA, Huang A, et al. Effect of a centralized prescription network on inappropriate prescriptions for opioid analgesics and benzodiazepines. CMAJ 2012;184:E852-6.

11. Research projects. Vancouver: Population Data BC; 2015; Available: www.popdata.bc.ca/ria/projects (accessed 2016 Feb. 19).

12. Updates from the drug programs. Vancouver: College of Physicians and Surgeons of British Columbia; 2015. Available: www.cpsbc.ca/ for-physicians/college-connector/2015-V03-03/06 (accessed 2015 May 15).

Affiliations: School of Population and Public Health (Smolina, Morgan), University of British Columbia; BC Centre for Disease Control (Smolina), Vancouver, BC; University of Toronto and St. Michael's Hospital (Persaud), Toronto, Ont.

Contributors: All of the authors contributed to drafting and revising the article, approved the final version to be published and agreed to act as guarantors of the work.

Acknowledgements: The authors thank Simon Hagens and Jeff Green from Canada Health Infoway for their insights on drug information system development and implementation. Kate Smolina and Steven Morgan are supported by a grant from the Canadian Institute for Health Research (CIHR); Kate Smolina is also supported through CIHR Banting Postdoctoral fellowship. Nav Persaud is supported by a PSI Graham Farquharson Fellowship. 